\title{
Spatial-Temporal Event-Driven Modeling for Occupant Behavior Studies Using Immersive Virtual Environments
}

\author{
Sanaz Saeidi ${ }^{1}$, Chanachok Chokwitthaya ${ }^{2}$, Yimin Zhu' ${ }^{3}$, Ming Sun ${ }^{4}$ \\ ${ }^{1}$ Department of Construction Management, Louisiana State University, Baton Rouge, USA; \\ 70803; Email: ssaeid1@ @ 1su.edu \\ ${ }^{2}$ Department of Construction Management, Louisiana State University, Baton Rouge, USA; \\ 70803; Email: cchokw1@ 1su.edu \\ ${ }^{3}$ Department of Construction Management, Louisiana State University, Baton Rouge, USA; \\ 70803; Email: yiminzhu@1su.edu \\ ${ }^{4}$ Department of Construction Management and Innovation, Heriot Watt University, Edinburgh, \\ UK: Email: m.sun@hw.ac.uk
}

\begin{abstract}
It is widely accepted that the prediction of building energy performance is strongly related to the occupancy parameters. Currently, existing buildings and laboratories are the main sources for collecting occupancy related data. However, using such data for predicting the energy consumption of future buildings can create a considerable amount of uncertainties. Recent studies show that Immersive Virtual Environments (IVEs) have the potential to generate design and context sensitive occupant-related data. However, extended observations (longitudinal data covering relevant spatial and temporal events) which are necessary for developing quantitative predictive models are impractical using conventional IVEs. To that end, the authors propose a Spatial-Temporal Event-
\end{abstract}


Driven (STED) modeling approach to enable IVEs for longitudinal studies. Using a single occupant office as case study, two sets of occupancy and lighting data, from IVEs and a comparable physical environment (in-situ), were collected. The occupancy/lighting data was organized in form of state transitions at six events (i.e., arrival in the morning, leaving for and returning from a short leave, leaving for and returning from a long leave, and leaving at the end of a day). It was hypothesized that the probabilities of the occupancy/lighting state transitions in a given event across the two experimental environments (i.e. IVE vs. in-situ) are not statistically different. Results revealed similar patterns at four of the six events $(\alpha=0.05)$, except at the short leave events. Thereby, STED modeling enabled the potential viability of IVEs for extended observations and generating data to support predictive models. Clearly, more basic research is needed to make data collection using IVEs more effective including a better understanding of virtual cue design and participant's physiological and psychological conditions at the time of experiments.

Keywords: Immersive Virtual Environment (IVE), occupant energy behavior, case study, building

\section{BACKGROUND}

Recent studies suggest that occupant behavior has a significant impact on building energy consumption [1] and has caused high performance buildings to fail in meeting their design expectations [2]. Meanwhile, work productivity, human health, and building energy efficiency are intertwined and heavily dependent on occupant comfort (e.g., [3], [4]). Thus, a better understanding of human and building interactions in different settings is critical to building design and operations. Currently, mainstream studies on occupant behaviors have been mainly conducted in-situ using actual buildings [5]. While such studies are important to the operations of existing buildings, results of those studies are often difficult to generalize and apply to other buildings or new designs [6]. This is one of the reasons that after decades of building performance research, 
performance gaps still exist [7]. In buildings where automated systems are used occupants' interactions with such automated systems (e.g. technology-user interactions, program design, and data analysis) are critical for the successful implementation of full automated systems $[8,9]$. Therefore, human-building interactions are a topic that will not be exempted from future research. Let alone to say that passive building designs are also gaining popularity [10,11].

The authors suggest a new approach, the application of immersive virtual environments (IVEs) for generating and examining occupant-related data during the preconstruction phases of a building project. IVE's are rich multisensory computer simulations that can afford the feeling of being mentally immersed or present in the simulations, i.e.,- - a virtual world [12].The level of immersion in Virtual Reality (VR) is dependent upon the graphic frame rate, overall extent of tracking, tracking latency, quality of the images, the field of view, the visual quality of the rendered scene, dynamics, and the range of the sensory modalities accommodated [13,14]. VR experiences can be classified into 1) fully immersive or first-order immersive systems that have a lot in common with our everyday experiences (e.g. head-mounted displays). Lower order VR systems are 2) semi-immersive (e.g. projection-based displays), and 3) non-immersive (e.g. desktop stereoscopic displays) complied with fewer immersion capabilities, however, they still offer some levels of presence $[15,16]$. The advantage of using IVEs for data collection is its ability to retain the control of an experimental environment, and its flexibility in designing experimental contexts. "IVE's attraction lies in the tendency for individuals to react in virtual reality as they would in the real-life situation.”[17]. They have been effectively utilized to testing situations that are too risky to be examined in reality, such as emergency evacuation in tunnels [18] [19] or hotels [20]. Furthermore, IVE applications have made an exceptionally useful contribution to cases with nonexisting testing platform or experiences that cannot be easily replicated in in-situ; for instance, 
building design review and analysis [21][22], the review of full scale physical mock-ups of hospital patient rooms [23][24], and architectural design [25][26][27]. Above all, IVE applications to occupant energy-use behavior studies are emerging [27] [28][29][30][31][32][33]. These studies have demonstrated the outstanding capabilities of IVEs to model: 1) building components such as rooms, spaces, windows, lights, or blinds, as well as their properties such as space layout and luminance levels; 2) states of a building component such as blinds close or open and lights on or off; 3) indoor environments specific to the purpose of a study, such as addressing visual, acoustic, and thermal comfort factors; and 4) interactions with building components such as operations of lights or blinds.

Although these capabilities are critical to modeling occupant energy behaviors, IVEs have not been used to develop quantitative predictive models yet. Typically, creating such models requires sufficient information about the variable of interest to enable establishing and examining the patterns in the data [34], which can only be achieved through extended observations (longitudinal data) or repeated measures. Whilst acquiring longitudinal data is not a problem in insitu studies or using surveys, it represents a significant challenge to IVE applications. In an IVE experiment, researchers typically cannot continuously put participants in IVEs for more than 20 to 30 minutes or request the same participant to participate in many experiments. Thus, collecting longitudinal data using conventional IVE designs is impractical. To better address this limitation of IVEs, the authors propose a Spatial-Temporal Event-Driven (STED) modeling approach, which selects and models a series of critical events and thus condenses a long period of observations such as days or seasons into a considerably shorter time such as a couple of hours. In other words, continuous observations are broken down into numerous measurable experimental units, which represent benchmarks subjected to the planned interventions of an experiment. If successful, this 
approach will enable longitudinal data collection in IVEs, which is critical to support a larger range of applications including predictive modeling than existing applications of IVEs in building design.

\section{THE SPATIAL-TEMPORAL EVENT-DRIVEN (STED) MODEL}

\section{Conceptual Framework}

Longitudinal studies supposedly contain a balanced coverage of observations based on the needs of research. Using a conceptual framework, this study was able to design a systematic method to generate sufficient data that will be useful for ensuring IVEs in extended observations. To begin with, the authors adopted four basic elements related to occupants and building energy performance, to describe the conceptual framework of a STED model, i.e., "State", "Context", "Event", and "Human (H)-Building(B) Interaction." In this study, State $\left(s_{i}, s_{i+1}, \ldots, s_{i+n}\right)$ is defined as the collective status of operations in different building spaces at a certain point of time, especially the conditions of building systems and components that are operable by human beings and have energy efficiency consequences. An example of the state of a building can be the lightuse condition of an entire building at 8:00am on a normal working day. Contexts are situational factors that are associated with and describe the state of a building, but not necessarily a part of it. For example, a contextual factor can be the season for describing the light-use state of a building at 8:00am, because the daylight condition in the winter can be significantly different from the summer at the same time point. Event $\left(e_{1}, e_{2}, \ldots, e_{k}\right)$ is an occurrence that triggers the change of a state or sets the foundation for future events to change a state. Thus, there are state changing events and non-state changing events. Finally, $H-B$ Interaction refers to a particular type of occupant actions to mitigate a thermal, visual, indoor air quality, or acoustic discomfort of an occupant such 
as turning on artificial lighting at 8:00am by an occupant, which is associated with a state change event.

At a higher level, states and events are interconnected, forming a constant loop between them (see Fig. 1). State $i$ is the initial status of a given set of spaces at a specific time point along the time span of a study. State $i$ will change to state $i+1$ upon the occurrence of an event. This structure allows researchers to connect space conditions and time, which is critical to designing experiments for longitudinal data collection in built environments.

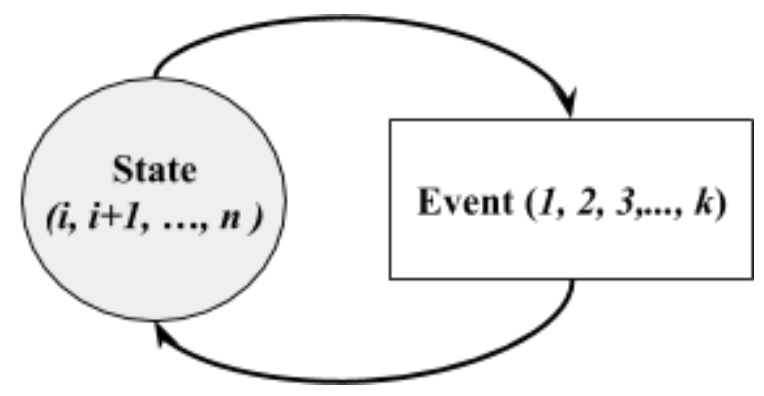

Fig. 1. State-Event Model

Fig. 2 displays a more extensive model of the state-event diagram that incorporate "occupant need", and "H-B interaction" into the state-event model. Occupant needs are defined as human motivation under the context preceding the occurrence of an event, and consequently trigger H-B interactions. In fact, the occurrence of an event can impact occupant's overall comfort and generate a desire for H-B interactions, which leads a state change. Thus, a state transition, the change in the collective status of a building and its component will take place. Window-opening, shade control, lighting control, thermostat control, electric equipment usage, and space occupancy status are among the most common H-B interactions people perform to maintain or pursue their general comfort indoors. 


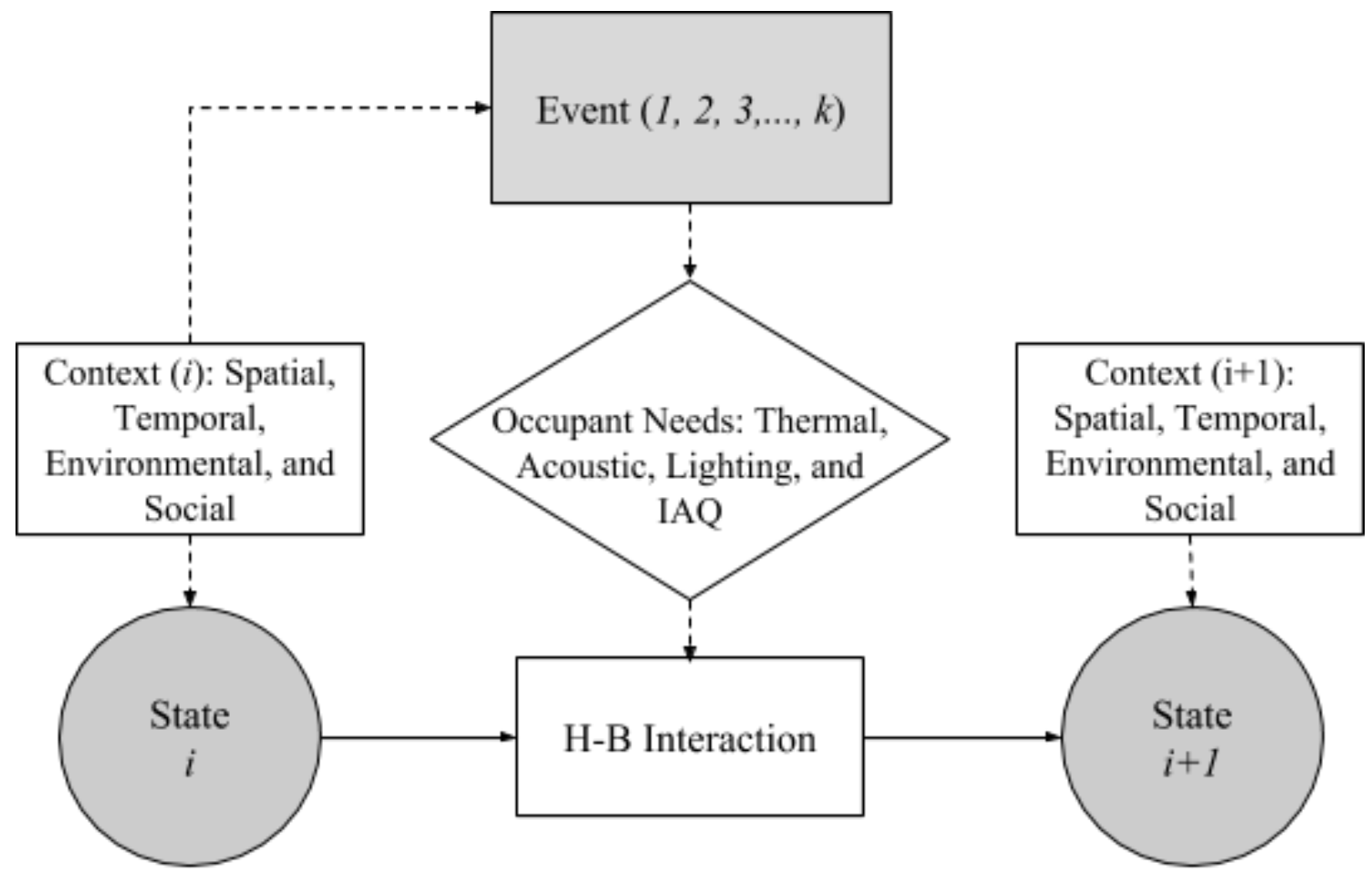

Fig. 2. STED Model

\section{Theoretical Framework}

Since state transitions are a key parameter to measure the impact of occupant behavior, this study uses a transition matrix to estimate all possible transitions from one state $\left(s_{i}\right)$ to the following state $\left(s_{i+1}\right)$. According to Fig. 2, the connection between two consecutive states is tightly related to possible events $\left(e_{k}\right)$ in between. Consequently, the likelihood of state transitions is essential dependent on paired transitions, i.e., from $s_{i}$ to $e_{k}$ and then from $e_{k}$ to $s_{i+1}$. Therefore, two conditional probabilities are used to describe a state transition from $s_{i}$ to $s_{i+1}$, the probability of the occurrence of an event given an initial state, $p\left(e_{k} \mid s_{i}\right)$, and the probability of an event leading to a succeeding state, $p\left(s_{i+1} \mid e_{k}\right)$. Hence, the probability of the occurrence of a state $\left(s_{i+1}\right)$ given a certain initial state $\left(s_{i}\right)$ is estimated by two conditional probabilities, $p\left(e_{k} \mid s_{i}\right)$ and $p\left(s_{i+1} \mid e_{k}\right)$, which is calculated by $p\left(s_{i+1} \mid s_{i}\right)=p\left(e_{k} \mid s_{i}\right) * p\left(s_{i+1} \mid e_{k}\right)$. 
The probability, $p\left(e_{k} \mid s_{i}\right)$, is calculated as follows. The number of occurrence of event $k$ $\left(n e_{k}\right)$ at state $i\left(s_{i}\right)$, is expressed as $n e_{k} s_{i}$ and used to construct a probability matrix $M$. For instance, the number of event 2 at the occurrence of state 0 is $n e_{2} s$.

$$
M=\left[\begin{array}{ccccc}
n e_{1} s_{0} & n e_{2} s_{0} & n e_{3} s_{0} & \ldots & n e_{l} s_{0} \\
n e_{1} s_{1} & n e_{2} s_{1} & n e_{3} s_{1} & \ldots & n e_{l} s_{1} \\
\vdots & \vdots & \vdots & \ldots & \vdots \\
n e_{1} s_{n} & n e_{2} s_{n} & n e_{3} s_{n} & \ldots & n e_{l} s_{n}
\end{array}\right]
$$

where, $l$ is the number of possible events, $n e_{k} \in\left(n e_{1}, n e_{2}, \ldots, n e_{l}\right)$; and $n$ is the number of possible states, $s_{i} \in\left(s_{0}, s_{1}, \ldots, s_{n}\right)$.

Thereafter, $p\left(e_{k} \mid s_{i}\right)$ is calculated by,

$$
p\left(e_{k} \mid s_{i}\right)=n e_{k} s_{i} / \sum_{j=1}^{l} n e_{j} s_{i}
$$

The collective probabilities are expressed using a matrix, $P_{e_{k} \mid s_{i}}$, shown below,

$$
P_{e_{k} \mid s_{i}}=\left[\begin{array}{ccccc}
p\left(e_{1} \mid s_{0}\right) & p\left(e_{2} \mid s_{0}\right) & p\left(e_{3} \mid s_{0}\right) & \ldots & p\left(e_{k} \mid s_{0}\right) \\
p\left(e_{1} \mid s_{1}\right) & p\left(e_{2} \mid s_{1}\right) & p\left(e_{3} \mid s_{1}\right) & \ldots & p\left(e_{k} \mid s_{1}\right) \\
\vdots & \vdots & \vdots & \ldots & \vdots \\
p\left(e_{1} \mid s_{i}\right) & p\left(e_{2} \mid s_{i}\right) & p\left(e_{3} \mid s_{i}\right) & \ldots & p\left(e_{k} \mid s_{i}\right)
\end{array}\right]
$$

Likewise, the probability, $P\left(s_{i+1} \mid e_{k}\right)$, is calculated as follows. The number of occurrence of state $i+1\left(n s_{i+1}\right)$ at event $\mathrm{k}\left(e_{k}\right)$ is expressed as $n s_{i+1} e_{k}$ and used to construct a matrix M'. For instance, the number of occurrence of state 2 at event 1 is $n s_{2} e_{1}$.

$$
M^{\prime}=\left[\begin{array}{cclll}
n s_{1} e_{1} & n s_{2} e_{1} & n s_{3} e_{1} & \ldots & n s_{n} e_{1} \\
n s_{1} e_{2} & n s_{2} e_{2} & n s_{3} e_{2} & \ldots & n s_{n} e_{2} \\
\vdots & \vdots & \vdots & \ldots & \vdots \\
n s_{1} e_{l} & n s_{2} e_{l} & n s_{3} e_{l} & \ldots & n s_{n} e_{l}
\end{array}\right]
$$

where, $l$ is the number of possible events, $e_{k} \in\left(e_{1}, e_{2}, \ldots, e_{l}\right)$; and $n$ is the number of possible states, $n s_{i} \in\left(n s_{1}, n s_{2}, \ldots, n s_{n}\right)$.

Then, $p\left(s_{i+1} \mid e_{k}\right)$ is calculated by,

$$
p\left(s_{i+1} \mid e_{k}\right)=n s_{i+1} e_{k} / \sum_{i=0}^{n-1} n s_{i+1} e_{k}
$$


The collective probabilities could be then combined into a matrix form, $P_{s_{i+1} \mid e_{k}}$, as shown below,

$$
P_{s_{i+1} \mid e_{k}}=\left[\begin{array}{ccccc}
p\left(s_{1} \mid e_{1}\right) & p\left(s_{2} \mid e_{1}\right) & p\left(s_{3} \mid e_{1}\right) & \ldots & p\left(s_{n} \mid e_{1}\right) \\
p\left(s_{1} \mid e_{2}\right) & p\left(s_{2} \mid e_{2}\right) & p\left(s_{3} \mid e_{2}\right) & \ldots & p\left(s_{n} \mid e_{2}\right) \\
\vdots & \vdots & \vdots & \ldots & \vdots \\
p\left(s_{1} \mid e_{k}\right) & p\left(s_{2} \mid e_{k}\right) & p\left(s_{3} \mid e_{k}\right) & \ldots & p\left(s_{n} \mid e_{k}\right)
\end{array}\right]
$$

Finally, the probability, $p\left(s_{i+1} \mid s_{i}\right)$, is determined as follow,

$$
\begin{aligned}
& p\left(s_{i+1} \mid s_{i}\right)=p\left(e_{k} \mid s_{i}\right) * p\left(s_{i+1} \mid e_{k}\right)
\end{aligned}
$$

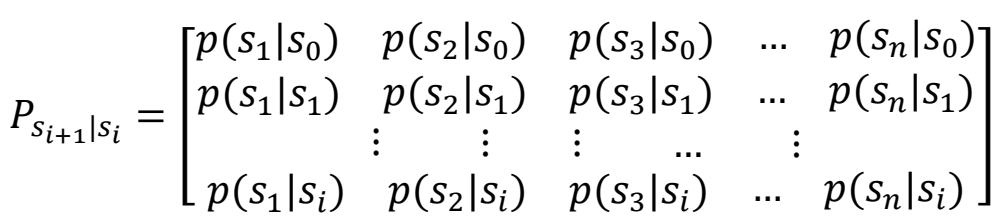

The rows of the matrix represent the initial state $\left(s_{i}\right)$ and the columns account for the succeeding state $\left(s_{i+1}\right)$. For instance, the probability of state 2 occurring after state 1 is determined by $p\left(s_{2} \mid s_{1}\right)$.

\section{RESEARCH OBJECTIVE, HYPOTHESIS, SIGNIFICANCE AND METHODOLOGY}

In the following section, the authors provide details regarding the research objective, hypothesis, significance, and methodology with respect to the STED modeling approach. In the research methodology section, the authors discuss a case study applied in this study, the design of IVEs based on the STED modeling approach, experiment design and procedure, data collection, and the analysis method.

\section{Objective}

The objective of this study is to obtain initial evidence that IVEs have potential for supporting longitudinal experimental studies. The authors applied STED modeling in designing a case study in order to emulate extended observations in IVEs, and examined the validity of state transitions based on data acquired from IVEs by comparing state transitions with data gathered from a 
comparable in-situ environment. The case study was focused on the replicability of events and state transitions across the two experimental settings. Thus, the key metric in this case study was the likelihood of state changes at selected events, and in more specific terms, the probability of state changes in occupancy/lighting patterns (state transitions).

\section{Hypothesis}

The authors hypothesize that given a set of logically related states and corresponding events, the STED modeling enables IVEs to produce longitudinal occupant behavior data in a short period of time, which are as reliable as observational studies conducted in-situ. It is expected that changing the experimental environment does not affect the state-event changes.

To test this hypothesis, the authors used transitional probabilities of the occupancy/lighting states in some selected events in to similar IVE and in-situ experimental setting:

$$
\begin{aligned}
& H_{0}: p\left(s_{i+1} \mid s_{i}\right)=p^{\prime}\left(s_{i+1} \mid s_{i}\right), i=0,1, \ldots, n \\
& H_{1}: p\left(s_{i+1} \mid s_{i}\right) \neq p^{\prime}\left(s_{i+1} \mid s_{i}\right), i=0,1, \ldots, n
\end{aligned}
$$

Where, $s_{i}$ is the initial state; $s_{i+1}$ is the succeeding state; $p\left(s_{i+1} \mid s_{i}\right)$ is the transition probability from $s_{i}$ to $s_{i+1}$ in IVEs; and $p^{\prime}\left(s_{i+1} \mid s_{i}\right)$ is the transition probability in the corresponding in-situ environment.

\section{Significance}

If IVEs are proven to be effective for collecting longitudinal data and support building energy behavior studies, they can significantly impact occupant behavior research. First, using IVEs represents a design context-sensitive alternative to existing methods of occupant energy behavior modeling, enabling inquiries that are difficult or impossible to do in-situ. Researchers can design different and critical virtual scenes that do not exist in reality and observe human responses in those scenes. Second, IVEs have been applied to simulations of specific and individual events but 
have not been used to perform experiments on occupant behavior related to a series of connecting events, which is common in reality. In in-situ studies, such models are often developed to simulate occupant behavior of using lighting systems, temperature set points, space occupancy, or blinds and windows [1]. The STED modeling approach will make IVEs more useful as a scientific data collection tool. Finally, existing data collection methods have limitations compared with using IVEs. For example, fully-outfitted laboratories, such as the zero-net energy laboratory at the University of North Texas and the Flexlab at the Lawrence Berkeley National Laboratory, are expensive, and reconfiguring such labs for various architectural designs requires significant resources.

\section{CASE STUDY}

\section{STED Modeling}

The STED modeling is to model critical events in a chronological order, representing long observations of states in reality. In the case study, the basic measurement is the operations on a lighting switch to determine the occupancy/lighting state transition, which is a snapshot of a space at two different time points representing the initial and subsequent status of a space. Considering the current limitation of virtual reality technologies, the authors selected a single occupancy office in the case study in order to reduce the effect of the extraneous variables. The spatial dimension of the STED model depicts the physical configurations of the single occupancy office space, whereas the temporal aspect of it simulates the sense of time and captures a series of state transitions within a specific time frame, such as a day. Events are determined based on research needs and the likelihood of state changes. Since most lighting adjustments during a day happen upon arrival and/or before departure [35], the authors have selected six typical events representing the arrivals and departures and investigated the occupancy/lighting status of the office space at those time 
points. Therefore, events in this study are broken down into: $e_{1}$ ) arrival at the office; $e_{2}$ ) intermediate (short) leave; $e_{3}$ ) return from intermediate short leave; $e_{4}$ ) intermediate (long) leave; $e_{5}$ ) return from intermediate long leave; $e_{6}$ ) departure (see Fig. 3).

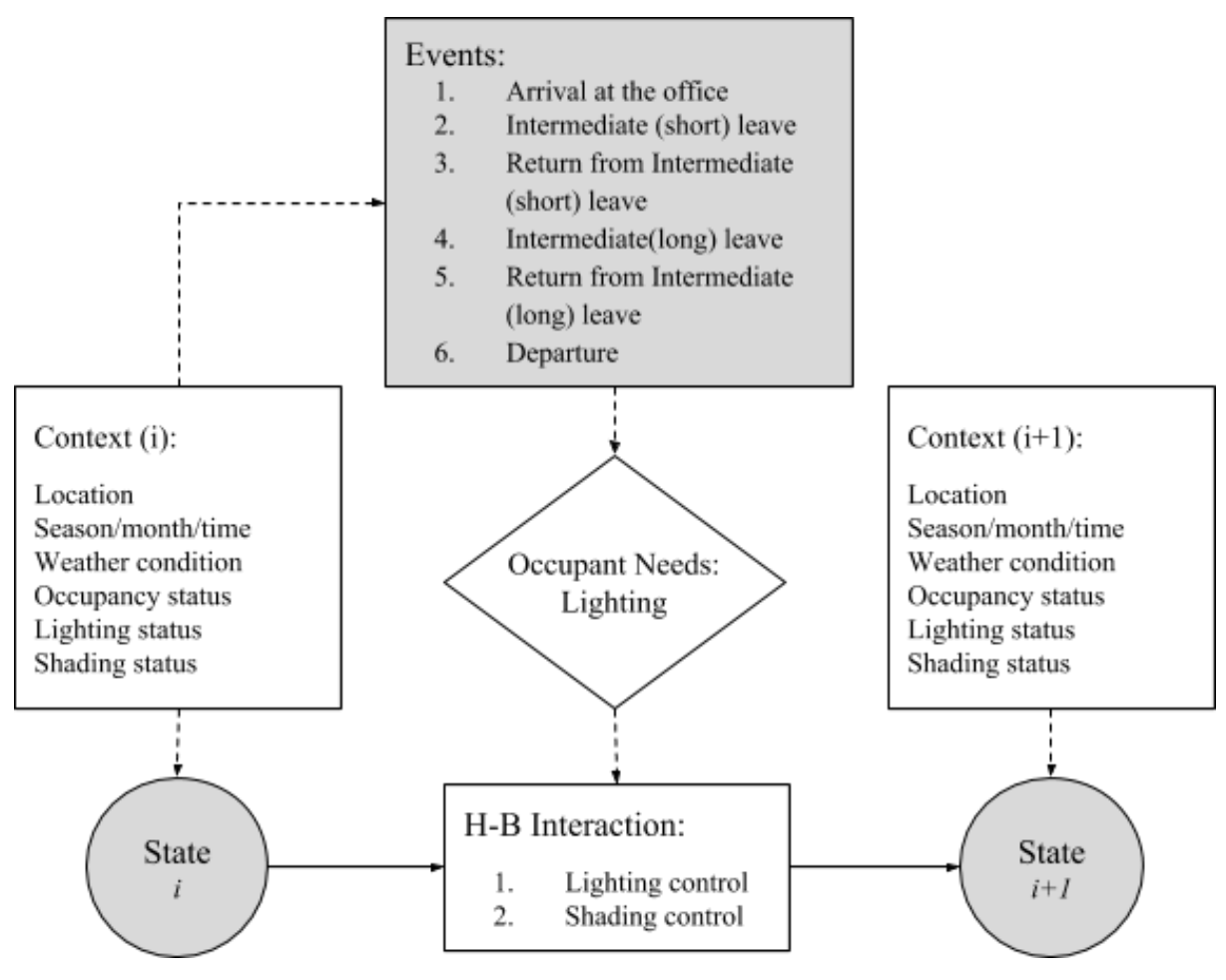

Fig. 3. STED Model (case study)

On the other hand, states are defined based on the combination of the occupancy and lighting status of the testing environments, which leads to four types of states: $s_{0}$ ) non-occupancy without artificial lighting; $s_{1}$ ) non-occupancy with artificial lighting; $s_{2}$ ) occupancy without artificial lighting; and $s_{3}$ ) occupancy with artificial lighting (see Fig. 4).
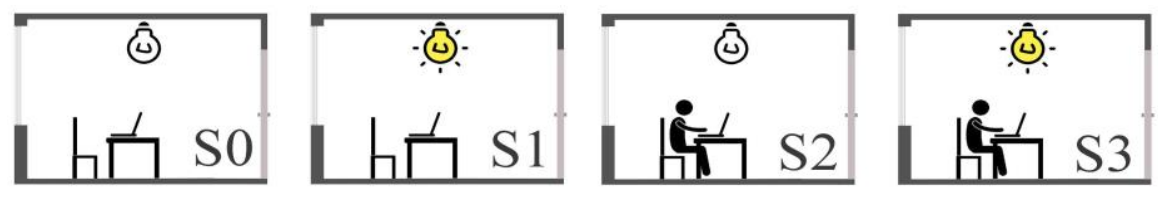

Fig. 4. Occupancy/lighting states (case study)

In larger scale studies, many other contextual factors such as the environmental and the social variables may also be considered and investigated for their possible influence on the 
occupancy/state behavioral pattern. This study chose a pairwise comparison (using IVE and insitu) to test the occupancy/lighting state changes and kept all other variables consistent across the two testing environments. Furthermore, the socio-demographic characteristics of the participants which would naturally have impact on the use of the space, have to be taken into account. However, in this study, the same participant took part in all data collection process and the major behavioral factors (e.g. attitudes, norms) were expected to remain consistent between the two experiments. Considering more contextual factors in the STED data collection method enables the researchers to gather more sensitive data.

\section{Method}

The case study involved two data collection methods, namely sensor (in-situ) and IVEs. The authors selected an on-campus single occupancy office at a major state university in the southern region of the United States. The office occupant (male, age: 30-40) was a faculty member of the university, who agreed to have sensors installed in his office for in-situ data collection and participate in the virtual reality experiments as well. The layout of the testing office and the place of the sensors are illustrated in Fig. 5. The testing office had a south-facing window with operable window-blinds as well as ceiling lights. The interior design of the office is shown in Fig. 6. 


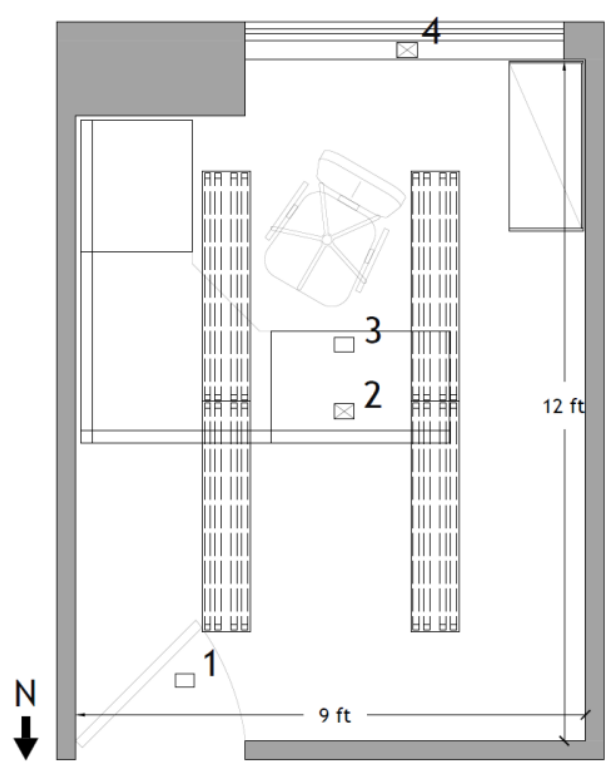

Fig. 5: Testing office layout

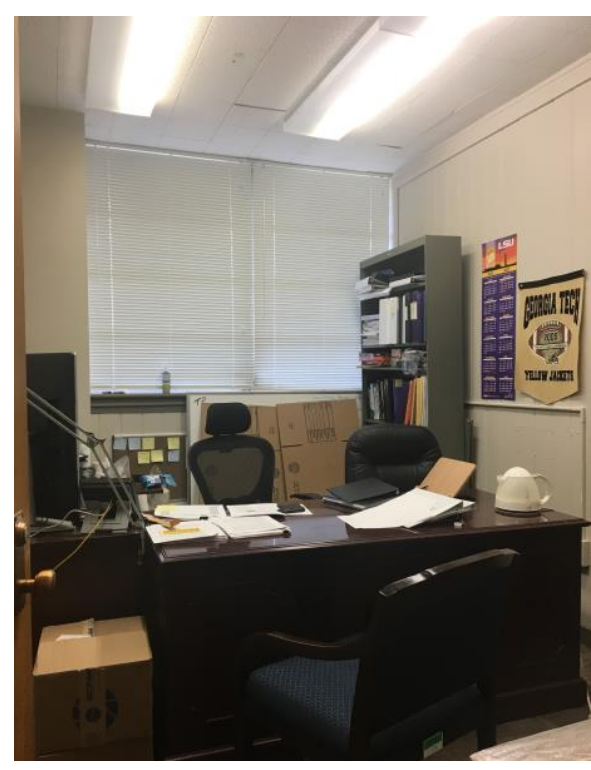

Fig. 6: Testing office photo

In-situ data collection was accomplished by using sensors to measure the occupancy pattern, the artificial lighting status, the lighting intensity, the indoor air temperature, and the relative humidity of the office. Table 1 presents a list of the sensors, their locations, and the purpose of using them, along with their pictures.

Table 1: Sensors, their locations and the purpose of using them

\begin{tabular}{|l|l|l|l|}
\hline \multicolumn{1}{|c|}{ Sensor Type/Model } & \multicolumn{1}{c|}{ Purpose } & \multicolumn{1}{c|}{ Location } & \multicolumn{1}{c|}{ Picture } \\
\hline $\begin{array}{l}\text { Onset UX90-005 HOBO } \\
\text { Occupancy/Light }\end{array}$ & $\begin{array}{l}\text { To identify the } \\
\text { occupancy } \\
\text { pattern and the } \\
\text { lighting status } \\
\text { (on/off) }\end{array}$ & $\begin{array}{l}\text { Sensor \# 1: above the } \\
\text { door; Sensor \# 3: above } \\
\text { the work plane. } \\
\text { (both attached to the } \\
\text { ceiling, facing } \\
\text { downward) }\end{array}$ & $\begin{array}{l}\text { Sensor \# 2: on the work } \\
\text { plane, at the height of } \\
\text { 2.8 ft.; Sensor \# 4: near } \\
\text { the window, at the } \\
\text { height of 4.1 ft. (both } \\
\text { sensors facing upward) }\end{array}$ \\
$\begin{array}{l}\text { Onset U12-012 HOBO } \\
\text { Temperature/Relative } \\
\text { Dumidity/Light/External Logger }\end{array}$ & $\begin{array}{l}\text { To measure the } \\
\text { light intensity, } \\
\text { ambient } \\
\text { temperature, and } \\
\text { relative humidity }\end{array}$ & \\
\hline
\end{tabular}

The sensors began monitoring and recording data from September 23 throughout October 27, 2016. The data from the occupancy/light data logger (marked as \#1 and \#3 in Fig.6) were 
recorded every second. The temperature/relative humidity/light intensity data logger (marked as \#2 and \#4 in Fig.6), was set to collect data every 5 seconds. The sensor readings were collected on a weekly basis. The data were exported to a computer and saved in a spreadsheet. The occupancy and the lighting status of the office were the main variables used in the analysis of this study; the indoor temperature and the relative humidity were recorded only as control variables. The indoor air temperature and the relative humidity of the testing office during the time span of this study were $72.40 \pm 2.13{ }^{\circ} \mathrm{F}$ and $54.11 \pm 6.03 \%$, respectively, which were mostly consistent during the occupancy period. They were also in the acceptable and recommended range of $68-76^{\circ} \mathrm{F}$ and $20 \%$ $60 \%$ respectively, according to the United States Occupational Safety and Health Administration [36]. The data collected from the sensors allowed the authors to observe major patterns of the occupancy/lighting and the state changes in the office. Consequently, the in-situ environment was reconstructed in IVEs and the observed events were modeled using cues. Eventually, the sensor data were used as a baseline for validating data collected in IVEs. The major variable of interest in this case study was the occupancy/lighting state change transitions which occurred at 128 events; 25 events of arrival at the office $\left(e_{1}\right), 32$ events of intermediate short leave $\left(e_{2}\right), 32$ events of returning from the intermediate short leave $\left(e_{3}\right), 8$ events of intermediate long leave $\left(e_{4}\right), 8$ events of returning from the intermediate long leave $\left(e_{5}\right)$, and 23 events of departure $\left(e_{6}\right)$. The initial occupancy/lighting state of the testing office, in the beginning of the experiment was always $s_{0}$ and the succeeding state of each event was the initial state of the second event.

\section{IVE Development}

IVE projects have some essential components that have to be taken into consideration; i.e. content, software, and display. The IVEs of this study are 3D computer-generated graphics modeled based on the testing office (Fig. 9). The initial 3D model of the IVEs was developed in 
AutoCAD 2016 and afterwards an image-editing application, Photoshop CC, was used to create its textures. The lighting maps were created in $3 \mathrm{~d}$ Max and then along with other components were imported into a game engine, Unreal Engine 4 (UE4), to program the IVE setting.

In designing the IVEs of this study, various types of virtual cues were designed and utilized to enhance the process of realizing the surroundings [37], and facilitate the flow of the experiment procedure. They included stimulatory cues, pertaining to the spatial and the temporal configuration of the IVE, as well as instructional cues. The former was used to simulate essential information about the experiment environment such as the sense of time, weather condition, and crowd (Fig. 7) and the latter helped the participant navigate within the IVEs, distinguish operable, virtual objects, and interact with those; e.g. as the participant hover the controller over the operable objects, they would start blinking, indicating that they are activated (Fig. 8). The study employed a narrative-along-the-experiment method to assist the participant to follow various steps of the experiment without the need to break his/her connection with the IVEs. Moreover, there were floating textual cues to inform the participant about the procedure of the experiment.

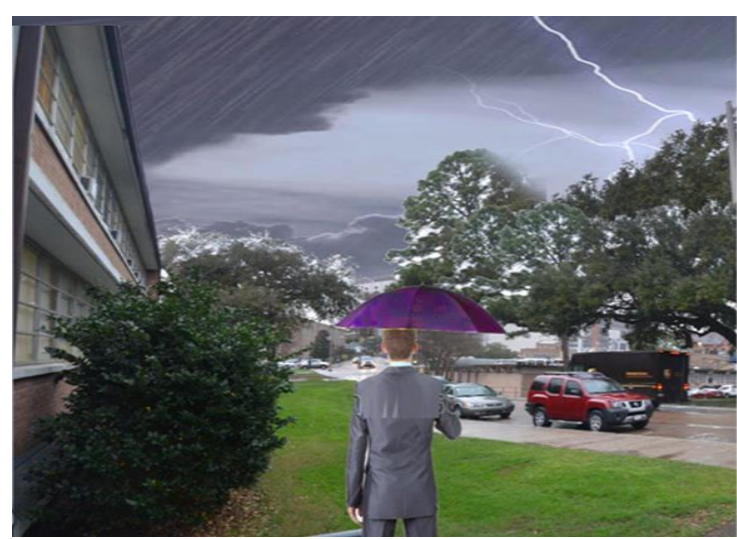

Fig. 7. Stimulatory cues

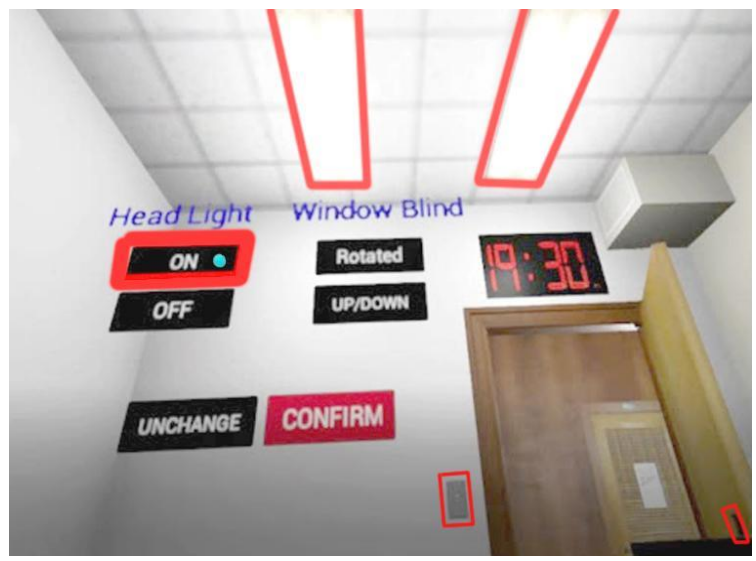

Fig. 8: Instructional cues 
Since this case study was related to the lighting-use behaviors of the participant, it was important to verify the illuminance specification of the IVEs. During the one-month in-situ observation, the range of the recorded lighting on the working area bounced around 400-600 lux. This illuminance range was in line with the standards and the recommended lighting for office task, i.e., 500 lux [38][39]. Thus, the illuminance level for the working area in the IVEs of this study was set to 500 lux and the RADIANCE software was used to verify the illuminance level based on three input variables of luminous flux (lumen), bulb size, and light color [40]. Essential game functions (e.g., interacting with light-switch and window-blind operations) were added to the IVEs through visual scripting system in UE4, which works based on the concept of a nodebased interface.

In order to experience immersion in a virtual reality experiment, a specific set of hardware, head-mounted display (HMD) and controllers, are required. HMD is a kind of computer display that is worn on the head which completely blocks out the vision and sound of the real world. The HMD that was used in this study had $2160 \times 1200$ resolution screen $\left(1080 \times 1200\right.$ per eye) and $110^{\circ}$ Field of View (FOV). Figure 9 displays the view of the IVEs in the HMD.

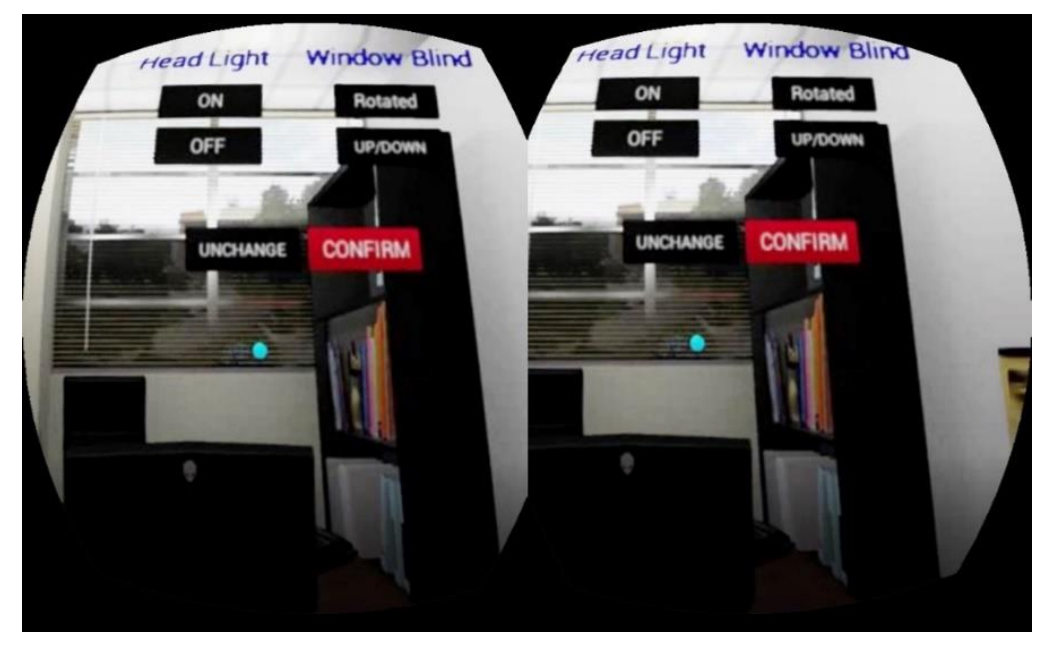

Fig. 9: IVE view from the HMD 
The type of IVE content greatly affects the quality of the virtual experience as well as the cost of its development. In essence, the more realistic and the more interactive the content, the more time-consuming and costly to produce. In fact, for a high-quality sensory experience, both the production and projection expenses are still high. At the time of writing this manuscript, a VRready computer and a high-end HMDs price would start from $\$ 2000$.

\section{Experiment Procedure}

This study was approved by the local Institutional Review Board. An informed consent form was sent to the participant and the signed form was collected before the first visit. The experiment procedure consisted of three major steps; a pre-experiment survey, IVE experiments for data collection, and the post-experiment surveys (Fig. 10).

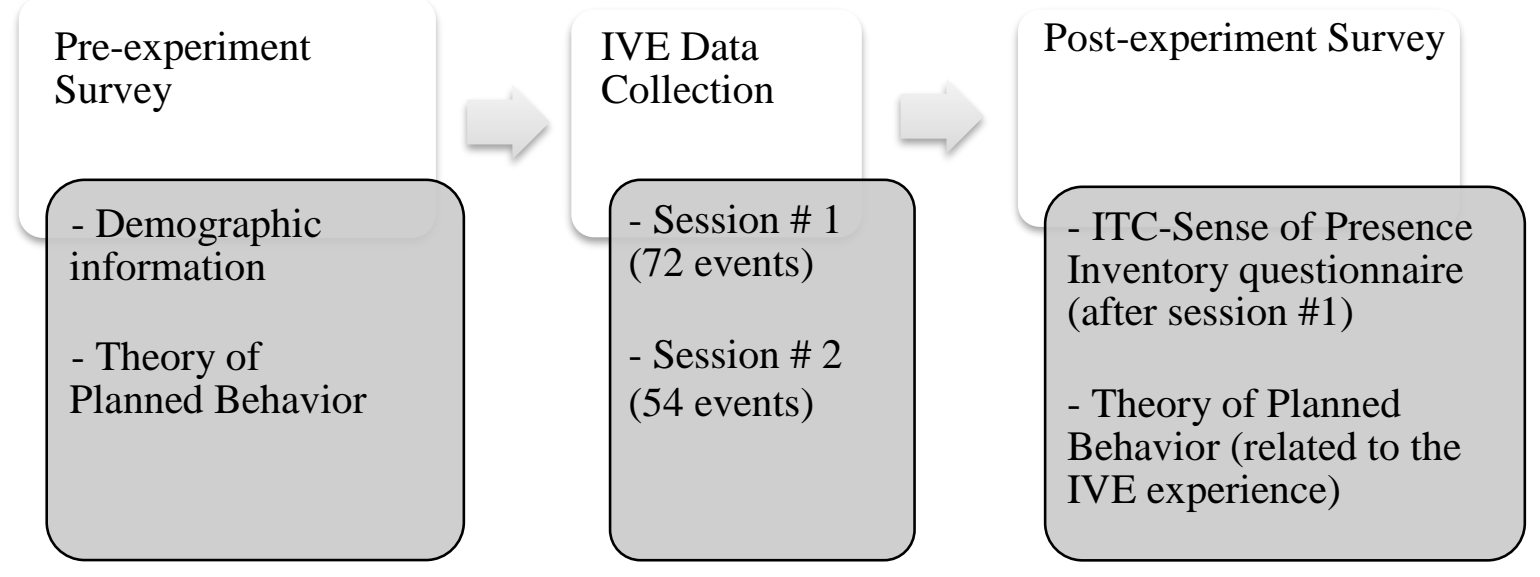

Fig. 10: Experiment procedure

The pre-experiment survey contained demographic information, knowledge of computer, and virtual reality experience inquiries. Furthermore, the constructs of the Theory of Planned Behavior (TPB) were incorporated in the survey to obtain information about the participant's tendency in the use of the lighting in the office. It is believed that a combination of measures of 
attitudes, norms, and perceived control belief to perform a behavior determines the intention to perform the behavior [41]; and the intention to perform a behavior, itself, is a proximal predictor of the actual behavior. The pre-experiment survey was used to find out the possible occupancy/lighting patterns in the office. It was administered two weeks prior to the IVE experiment, using a web-based survey tool ( $1-7$ Likert scale). The IVE experiment was carried out in two separate sessions, with one week gap in between. Before the IVE experiment, the participant was required to attend a familiarization (training) session, so that all the necessary actions with the VR tools, navigating through menus and within the IVEs, and responding to the virtual stimuli can be mastered.

The end result of the IVE experiments were the data related to the occupancy/lighting state change transitions which happened at 126 events, in total; 18 events of arrival at the office $\left(e_{1}\right), 18$ events of intermediate short leave $\left(e_{2}\right), 18$ events of returning from the intermediate short leave $\left(e_{3}\right), 18$ events of intermediate long leave $\left(e_{4}\right), 18$ events of returning from the intermediate long leave $\left(e_{5}\right)$, and 36 events of departure $\left(e_{6}\right)$. The initial occupancy/lighting state of the virtual office, in the beginning of the experiment was always set to $s_{0}$ and the succeeding state of each event became the initial state of the second event. Events in this study were established and ordered in a continuous chronological succession (i.e. starting with the arrival at the office in the morning) without an interruption. The duration of each event in the IVE experiment did not exceed 2 minutes and after every 12 events, there was a 5-10 minutes break. Each session lasted about 70 minutes in total.

All interactions with the lighting fixtures and window-blinds, the final decision on the lighting choice, and the intensity of the light were recorded during the IVE experiments. The output data from the IVEs were then recorded and stored in text format for the assessments. At the end, 
participant's subjective virtual reality experience was recorded using the ITC Sense of Presence Inventory (ITC-SOPI) instrument [42]. This questionnaire contained 44 items (1-5 Likert scale) and was administered upon the completion of the first IVE session. The second session of the IVE experiment was conducted after 10 days and the procedure of it was the same as the first session. However, there was an additional post-experiment TPB survey, investigating the perception of the behavioral control factors in the IVEs.

\section{Data Processing}

The in-situ data collected from sensors were extracted and analyzed as follows. Data from sensor \#3 which was located next to the ceiling lighting fixture was used to determine the lighting status (on/off) of the testing office. This sensor was supported with a light pipe accessory to eliminate effects of ambient light ensuring the most accurate readings. Additionally, the illuminance level of the work plane was identified by the use of sensor \#2 which then helped to confirm the readings from sensor \#3. To identify the occupancy status of the office, arrivals, and departures the data from both sensors \#1 and \#3 were simultaneously utilized. The detected motion by sensor \#3 determined the office's occupancy status, i.e., when this sensor showed motion for at least two minutes, it indicated that the office was occupied. The actions of entering and departing the office were assessed by the order of the two sensors that sensed a motion. For instance, if sensor \#1 detects a motion before sensor \#3, it would indicate that the subject has entered the office. Otherwise, if sensor \#1 monitors a motion after sensor \#3, it shows that the office has already been occupied — so, that would be a departure event from the office. Sensor \#4, located near the window, was mainly used to estimate the window blind (up/down) status. However, this type of information is not reported in this manuscript. 
Events were determined based on the time and the duration of the arrivals and departures; and states were identified by disclosing both the occupancy and the lighting status of the testing office. The first state change occurring in the morning, from non-occupied state (either $s_{0}$ or $s_{1}$ ) to occupied (either $s_{2}$ or $s_{3}$ ), was considered the initial arrival at the office. All lighting state changes during this study's timeline happened upon the participant's arrival at or departure from the office. Moreover, the intermediate leaves during the day were classified into long and short leaves; absences shorter than 60 minutes were considered as short intermediate leaves and those longer than 60 minutes as long intermediate leaves. The last departure was leaving the office for the day. Afterwards, the frequency and the probability of transitions from one state to another were arithmetically calculated. Algorithms used to organize and analyze the data were developed using Microsoft Excel, Matlab, and Python.

As discussed before, the relationship between states and events were defined as matrix $P_{e_{k} \mid s_{i}}$ and matrix $P_{s_{i+1} \mid e_{k}}$. The first matrix represents the likelihood that event $k$ occurs at the state $i$; and the latter demonstrates the likelihood that state $i+1$ is the succeeding occupancy/lighting status of the indoor setting.

$$
\begin{gathered}
P_{e_{k} \mid s_{i}}=\left[\begin{array}{llllll}
p\left(e_{1} \mid s_{0}\right) & p\left(e_{2} \mid s_{0}\right) & p\left(e_{3} \mid s_{0}\right) & p\left(e_{4} \mid s_{0}\right) & p\left(e_{5} \mid s_{0}\right) & p\left(e_{6} \mid s_{0}\right) \\
p\left(e_{1} \mid s_{1}\right) & p\left(e_{2} \mid s_{1}\right) & p\left(e_{3} \mid s_{1}\right) & p\left(e_{4} \mid s_{1}\right) & p\left(e_{5} \mid s_{1}\right) & p\left(e_{6} \mid s_{1}\right) \\
p\left(e_{1} \mid s_{2}\right) & p\left(e_{2} \mid s_{2}\right) & p\left(e_{3} \mid s_{2}\right) & p\left(e_{4} \mid s_{2}\right) & p\left(e_{5} \mid s_{2}\right) & p\left(e_{6} \mid s_{2}\right) \\
p\left(e_{1} \mid s_{3}\right) & p\left(e_{2} \mid s_{3}\right) & p\left(e_{3} \mid s_{3}\right) & p\left(e_{4} \mid s_{3}\right) & p\left(e_{5} \mid s_{3}\right) & p\left(e_{6} \mid s_{3}\right)
\end{array}\right] \\
P_{s_{i+1} \mid e_{k}}=\left[\begin{array}{llll}
p\left(s_{0} \mid e_{1}\right) & p\left(s_{1} \mid e_{1}\right) & p\left(s_{2} \mid e_{1}\right) & p\left(s_{3} \mid e_{1}\right) \\
p\left(s_{0} \mid e_{2}\right) & p\left(s_{1} \mid e_{2}\right) & p\left(s_{2} \mid e_{2}\right) & p\left(s_{3} \mid e_{2}\right) \\
p\left(s_{0} \mid e_{3}\right) & p\left(s_{1} \mid e_{3}\right) & p\left(s_{2} \mid e_{3}\right) & p\left(s_{3} \mid e_{3}\right) \\
p\left(s_{0} \mid e_{4}\right) & p\left(s_{1} \mid e_{4}\right) & p\left(s_{2} \mid s_{4}\right) & p\left(s_{3} \mid s_{4}\right) \\
p\left(s_{0} \mid e_{5}\right) & p\left(e_{1} \mid e_{5}\right) & p\left(e_{2} \mid e_{5}\right) & p\left(s_{3} \mid e_{5}\right) \\
p\left(s_{0} \mid e_{6}\right) & p\left(e_{1} \mid e_{6}\right) & p\left(e_{2} \mid e_{6}\right) & p\left(s_{3} \mid e_{6}\right)
\end{array}\right]
\end{gathered}
$$

After defining the probabilities of the state to event and event to the next state, the probability of all possible state transition will be shown in $P_{s_{i+1}} \mid e_{k}$ as follows: 


$$
P_{s_{i+1} \mid s_{i}}=\left[\begin{array}{llll}
p\left(s_{0} \mid s_{0}\right) & p\left(s_{1} \mid s_{0}\right) & p\left(s_{2} \mid s_{0}\right) & p\left(s_{3} \mid s_{0}\right) \\
p\left(s_{0} \mid s_{1}\right) & p\left(s_{1} \mid s_{1}\right) & p\left(s_{2} \mid s_{1}\right) & p\left(s_{3} \mid s_{1}\right) \\
p\left(s_{0} \mid s_{2}\right) & p\left(s_{1} \mid s_{2}\right) & p\left(s_{2} \mid s_{2}\right) & p\left(s_{3} \mid s_{2}\right) \\
p\left(s_{0} \mid s_{3}\right) & p\left(s_{1} \mid s_{3}\right) & p\left(s_{2} \mid s_{3}\right) & p\left(s_{3} \mid s_{3}\right)
\end{array}\right]
$$

The above formulas are applicable to both the in-situ and the IVE experiments. That is, there will be one set of transition matrix $\left(P_{s_{i+1} \mid s_{i}}\right)$ for each single event $\left(e_{k}\right)$ in in-situ and a corresponding transition matrix $\left(P_{s_{i+1}}^{\prime} \mid s_{i}\right)$ for the equivalent event $\left(e_{k}\right)$ in IVE. Therefore, six $4 \mathrm{x}$ 4 transition matrices will be produced $(k=6 ; s=4)$ for each of the IVE and the in-situ observations. As an example, the process of computing one of the state transitions is presented in Table 2. The probability of the initial state of $s_{i}=0$ to a succeeding state of $s_{i+1}=3$, at a given event of $e_{1}$, in the in-situ and in IVE are, respectively, $p\left(\mathrm{~s}_{3} \mid s_{0}\right)$ and $p^{\prime}\left(s_{3} \mid s_{0}\right)$.

Table 2. Sample state-event transition calculations in in-situ and IVE

\begin{tabular}{|ll|ll|}
\hline In-situ & & IVE & \\
$\boldsymbol{p}\left(\boldsymbol{e}_{\boldsymbol{k}} \mid \boldsymbol{s}_{\boldsymbol{i}}\right)$ & $\begin{array}{l}p\left(e_{1} \mid s_{0}\right)=n e_{1} s_{0} / \sum_{j=1}^{6} n e_{j} s_{0} \\
=36 / 45=0.8\end{array}$ & $\boldsymbol{p}^{\prime}\left(\boldsymbol{e}_{\boldsymbol{k}} \mid \boldsymbol{s}_{\boldsymbol{i}}\right)$ & $\begin{array}{l}p^{\prime}\left(e_{1} \mid s_{0}\right)=n e^{\prime}{ }_{1} s^{\prime}{ }_{0} / \sum_{j=1}^{6} n \boldsymbol{e}_{j}{ }_{j} s_{0} \\
=18 / 46=0.39\end{array}$ \\
\hline $\boldsymbol{p}\left(\boldsymbol{s}_{\boldsymbol{i}+\mathbf{1}} \mid \boldsymbol{e}_{\boldsymbol{k}}\right) \begin{array}{l}p\left(s_{3} \mid e_{1}\right)=n s_{3} e_{1} / \sum_{i=0}^{n-1} n s_{3} e_{1} \\
=25 / 25=1\end{array}$ & $\boldsymbol{p}^{\prime}\left(\boldsymbol{s}_{\boldsymbol{i}+\mathbf{1}} \mid \boldsymbol{e}_{\boldsymbol{k}}\right) \begin{array}{l}p^{\prime}\left(s_{3} \mid e_{1}\right)=n s^{\prime}{ }_{3} e_{1}{ }_{1} / \sum_{i=0}^{n-1} n s^{\prime}{ }_{3} e_{1}^{\prime} \\
=36 / 36=1\end{array}$ \\
\hline $\boldsymbol{P}\left(\boldsymbol{s}_{\boldsymbol{i}} \mid \boldsymbol{s}_{\boldsymbol{i}+\mathbf{1}}\right)$ & $\begin{array}{l}p\left(s_{3} \mid s_{0}\right)=p\left(e_{1} \mid s_{0}\right) * p\left(s_{3} \mid e_{1}\right) \\
=0.8 * 1=0.8\end{array}$ & $\boldsymbol{P}^{\prime}\left(\boldsymbol{s}_{\boldsymbol{i}} \mid \boldsymbol{s}_{\boldsymbol{i}+\mathbf{1}}\right)$ & $\begin{array}{l}p^{\prime}\left(s_{3} \mid s_{0}\right)=p^{\prime}\left(e_{1} \mid s_{0}\right) * p^{\prime}\left(s_{3} \mid e_{1}\right) \\
=0.39 * 1=0.39\end{array}$ \\
\hline
\end{tabular}

There has been many state transitions in each matrix that would be impossible (e.g., $p\left(s_{1} \mid s_{0}\right)$ to happen or not probable (e.g., $p\left(s_{2} \mid s_{0}\right)$ at $\left.e_{1}\right)$ in this case study; henceforth, they had zero probabilities. Given that, only non-zero state transitions were collected and listed for the statistical analysis (see Table 3).

\section{Data Analysis}

Using the collected sample data, a statistical hypothesis testing was used to determine whether the case study provides enough evidence to accept the study's proposition. In essence, the case study 
is to provide statistical proof of similarity between the IVE and in-situ datasets. It was, in fact, intended to see whether changing the experimental environment would have an impact on the outcome of the study. The major response (outcome) variable of this case study was the probability of the occupancy/lighting state changes prior and after the events, while the independent (manipulated) variable was the experimental environment, i.e., in-situ vs. IVE. Table 3 represents the frequency distribution of the occupancy/lighting state transitions at each event in-situ and in IVEs, as well as the $p$-values associated with the hypothesis test.

Table 3: Statistical significant test

\begin{tabular}{|c|c|c|c|c|c|c|c|}
\hline \multirow{3}{*}{\multicolumn{2}{|c|}{ Events }} & \multirow{3}{*}{$\begin{array}{c}\text { State } \\
\text { Transition } \\
\left(s_{i+1} \mid s_{i}\right)\end{array}$} & \multicolumn{4}{|c|}{$\begin{array}{c}\text { Frequency distribution of } \\
\text { the State Transitions }\end{array}$} & \multirow{3}{*}{$\begin{array}{c}P- \\
\text { value }\end{array}$} \\
\hline & & & \multicolumn{2}{|c|}{ In-situ } & \multicolumn{2}{|c|}{ IVE } & \\
\hline & & & $O$ & $X$ & $O$ & $X$ & \\
\hline$e_{1}$ & Arrival at the office & $\left(s_{3} \mid s_{0}\right)$ & 25 & 0 & 18 & 0 & 1 \\
\hline \multirow[t]{2}{*}{$e_{2}$} & \multirow[t]{2}{*}{ Intermediate (short) leave } & $\left(s_{0} \mid s_{3}\right)$ & 2 & 28 & 10 & 8 & $<0.05 *$ \\
\hline & & $\left(s_{1} \mid s_{3}\right)$ & 30 & 2 & 8 & 10 & $<0.05^{*}$ \\
\hline \multirow[t]{3}{*}{$e_{3}$} & \multirow[t]{3}{*}{ Return from intermediate (short) leave } & $\left(s_{2} \mid s_{0}\right)$ & 1 & 31 & 0 & 18 & 1 \\
\hline & & $\left(s_{3} \mid s_{0}\right)$ & 1 & 31 & 10 & 8 & $<0.05^{*}$ \\
\hline & & $\left(s_{3} \mid s_{1}\right)$ & 30 & 2 & 8 & 10 & $<0.05 *$ \\
\hline \multirow[t]{2}{*}{$e_{4}$} & \multirow[t]{2}{*}{ Intermediate (long) leave } & $\left(s_{0} \mid s_{3}\right)$ & 7 & 1 & 18 & 0 & 0.31 \\
\hline & & $\left(s_{1} \mid s_{3}\right)$ & 1 & 7 & 0 & 18 & 0.31 \\
\hline \multirow[t]{3}{*}{$e_{5}$} & \multirow[t]{3}{*}{ Return from intermediate long leave } & $\left(s_{2} \mid s_{0}\right)$ & 0 & 8 & 1 & 17 & 1 \\
\hline & & $\left(s_{3} \mid s_{0}\right)$ & 7 & 1 & 17 & 1 & 0.53 \\
\hline & & $\left(s_{3} \mid s_{1}\right)$ & 1 & 7 & 0 & 18 & 0.31 \\
\hline \multirow[t]{4}{*}{$e_{6}$} & \multirow[t]{4}{*}{ Departure } & $\left(s_{0} \mid s_{2}\right)$ & 1 & 22 & 1 & 35 & 1 \\
\hline & & $\left(s_{1} \mid s_{2}\right)$ & 0 & 23 & 0 & 36 & 1 \\
\hline & & $\left(s_{0} \mid s_{3}\right)$ & 21 & 2 & 35 & 1 & 0.55 \\
\hline & & $\left(s_{2} \mid s_{3}\right)$ & 1 & 22 & 0 & 36 & 0.39 \\
\hline
\end{tabular}

Note: O: Count number of occurrences, X: Count number of non-occurrences

This study used a nonparametric statistical test, namely, Fisher's exact test to find out if there is any nonrandom association between the studied variables of the research. This test is applicable when the variables are nominal and it is more accurate than other independence tests (e.g. chi-square) when the sample is small. The null hypothesis of this test is that there is no association between the two variables of the research, such that the proportions for the first variable 
are different among values of the other variable. In the case of this study, that is, the probability of the occupancy/lighting state transitions are not influenced by being in any of the two experimental settings $\left(H_{0}: p\left(s_{i+1} \mid s_{i}\right)=p^{\prime}\left(s_{i+1} \mid s_{i}\right), i=0,1, \ldots, n\right)$. Fisher's exact test analyzes the two-by-two contingency tables and examines the equivalence of the probability distributions of the state transitions in the IVE and in-situ experiments. The $p$-values greater than 0.05 would retain the null hypothesis, suggesting that the two applied methods of data collection generate similar outcomes (at the 0.05 level of significance) and the data is independent from the studied tools, i.e., IVEs vs. in-situ. Statistical analysis of this study was performed in SAS 9.4 (Statistical Analysis System) and JMP 13 (see Fig. 10).

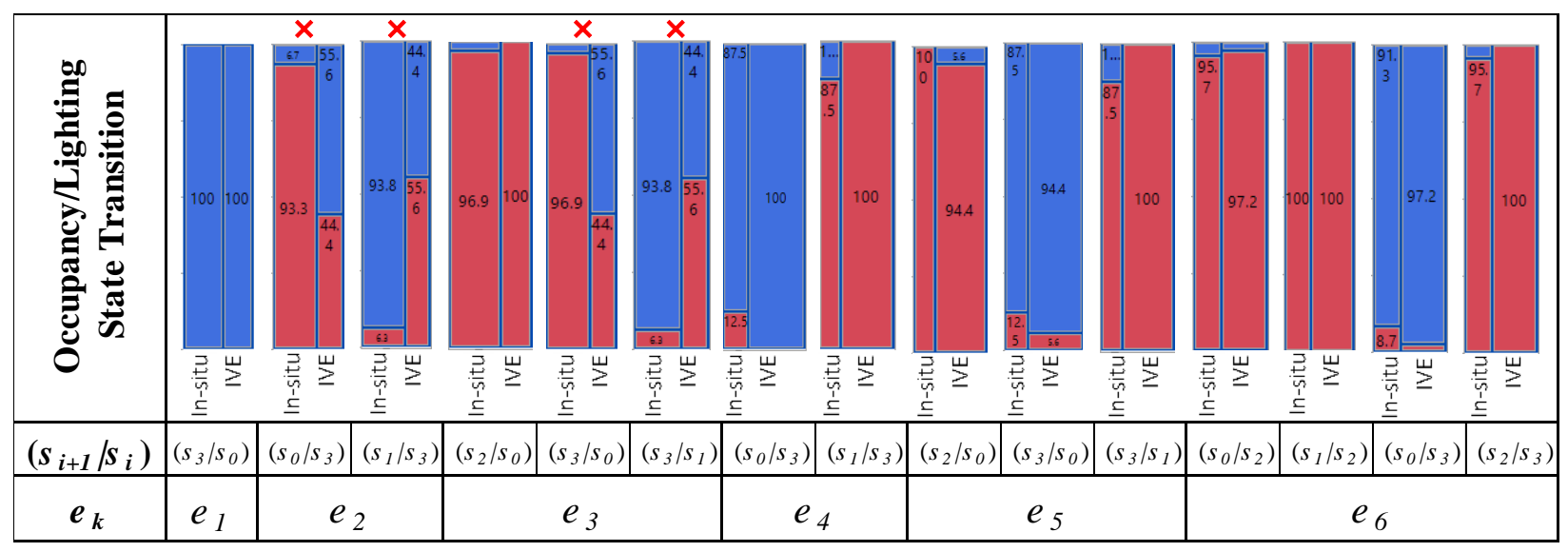

X Statistically significant (p-value less than 0.05)

Probability of occurrences

- Probability of non-occurrences

Fig. 10: Analysis of contingency tables

\section{Results and Interpretations}

The results of the Fisher's exact test given in Table 3 and illustrated in Figure 10 clearly showed that the majority of the occupancy/lighting state transitions were statistically comparable between the IVE and in-situ environments. In $e_{1}$, the only possible state transition was $\left(s_{3} \mid s_{0}\right)$ which was also the only occurred state transition and the result of the statistics revealed a complete 
consistency in the outcomes across two experimental settings ( $p$-value $=1)$. That is, regardless of being in IVE or in-situ, $s_{0}$ always led to $s_{3}$ at the event of the arrival at the office. Similar to the $e_{1}$, $e_{6}$ showed that the IVEs were able to closely match in-situ observations. The reported $p$-values from the statistical significance test for comparing $\left(s_{0} \mid s_{2}\right), \quad\left(s_{1} \mid s_{2}\right), \quad\left(s_{0} \mid s_{3}\right), \quad\left(s_{2} \mid s_{3}\right)$ and their counterparts, were greater than 0.05 , which suggest that there was no experimental setting effect on any of the occupancy/lighting state transitions at $e_{6}$.

Additionally, the case study investigated the intermediate leaves (short and long) and returns to the office. In the event of the long leaves $\left(e_{4}\right)$ and returns to the office from the long leaves $\left(e_{5}\right)$ the observed occupancy/lighting state transitional probabilities in IVEs perfectly corresponded with their counterpart in-situ ( $p$-value>0.05). Yet, there were inconsistencies in the event of the short leaves $\left(e_{2}\right)$ and returns to the office from short leaves $\left(e_{3}\right)$. At $e_{2}$, the probabilities of transition from $s_{3}$ to $s_{0}$ and from $s_{3}$ to $s_{1}$ in IVEs was statistically different than those in-situ $(p$ value $<0.05)$. More specifically, in IVEs the tendency of turning the lights off upon the short leaves was significantly higher. Consequently, the occupancy/lighting state transitions at $e_{3}$, which was essentially dependent on the chosen lighting status in $e_{2}$, were different from the in-situ ( $p$-value $<$ 0.05) and could not follow the same pattern as in-situ. However, in this case study, the cumulative record of the arrivals at the office (regardless of the initial lighting status) clearly showed that " $s 3$ " was the most probable office status in both the in-situ observation and IVEs. Considering that the only observed discrepancy between the IVE and the in-situ occupancy/lighting state transitions occurred at $e_{2}$ and $e_{3}$, the authors believe that the IVE design or the associated cues might not have been able to properly characterize those events. The cues that were used to represent $e_{2}$ and $e_{3}$, intermediate (short) leaves and returns from/to the office, were mainly auditory cues, such as a voice message on the phone, asking the participant to assist a student in the next-door office, or 
asking the participant to stop by the secretaries' office for a quick business affair. However, the duration in which the participant was expected to be involved with such activity was not directly stated throughout the message. As a matter of fact, open-ended messages of this kind could be personally interpreted, and the participant might draw his/her own conclusion about it. That is to say, the messages could be delivered and perceived in a different way rather than what the study planned to; thus, when the message is not clearly understood, the participant's response could be totally conditioned based on his/her subjective interpretation.

\section{IVE ECOLOGICAL VALIDITY}

According to Witmer [43], "the effectiveness of Virtual Environments (VEs) has often been linked to the sense of presence reported by users of those VEs." The perception of being present is crucial in IVEs, since the more a person feels presence in a virtual environment, the more his/her responses would match those in the physical environment $[43,44]$. Thus, the authors administered a wellknown presence instrument, ITC-SOPI, in order to take this factor into account. To determine if the IVEs are effective, the authors compared the results with previous studies (Table 4).

Table 4: Presence measurement scores comparison (mean \pm Standard Deviation)

\begin{tabular}{|c|c|c|c|c|}
\hline $\begin{array}{c}\text { ITC_SOPI } \\
\text { Measurements }\end{array}$ & $\begin{array}{c}\text { Case } \\
\text { Study }\end{array}$ & $\begin{array}{c}\text { Lighting use } \\
\text { behavior in } \\
\text { IVE (22) }\end{array}$ & $\begin{array}{c}\text { Thermal } \\
\text { Comfort in } \\
\text { IVE (23) }\end{array}$ & $\begin{array}{c}\text { Physiological } \\
\text { monitoring in } \\
\text { IVE (24) }\end{array}$ \\
\hline Engagement & 4.38 & $3.58 \pm 0.55$ & $3.44 \pm 0.48$ & $3.15 \pm 0.29$ \\
\hline Spatial Presence & 3.95 & $3.36 \pm 0.67$ & $3.37 \pm 0.55$ & $3.06 \pm 0.49$ \\
\hline Naturalness & 4 & $4.16 \pm 0.77$ & $3.52 \pm 0.61$ & $3.04 \pm 0.62$ \\
\hline Negative Effects & 3.33 & $2.38 \pm 0.72$ & $2.61 \pm 0.62$ & $2.55 \pm 0.74$ \\
\hline
\end{tabular}

The factors and items contributing to this instrument consist of Spatial Presence, Engagement, Naturalness, as well as the Negative Effects. Comparing with previous studies, the IVEs in this study have the following characteristics: 
1. The high scores of the "Spatial Presence" and "Engagement" were strong indication that the IVE setting of this study provided an adequate sense of attachment to the displayed environment, which afforded some sort of interactions.

2. This IVE was successful in drawing the participant's attention in terms of the "Naturalness" of the scenes and believability of its contents.

3. Even though the factor of "Negative Effect" scored the lowest in this study, it was higher than that of in the other studies conducted by the authors. The authors tried to minimize negative effects by allocating a five-minute break between each sub-session of the experiment.

The TPB survey, on the other hand, provided useful insight about the participant's tendency in the use of artificial lighting. The pre-experiment survey covered all the necessary measurements of the TPB (i.e., attitude, social norms, personal norm, perceived control belief, and actual control belief) were included in the questionnaire to study the participant's general behavioral intention. Thus, experimenters learned the exact way the participant tends to interact with the lighting in his real life (surveys are attached in the appendices). In the post-experiment survey, TPB measurements were designed and translated into the context of the IVE (e.g., social norms: "Even though I was in a virtual setting, I would still consider how my decision on the use of light would be evaluated by others"). The goal of using the TPB survey was to discover any existing causes of discrepancies in the occupancy/lighting behavioral patterns across the two testing environments. Indeed, the pre-experiment TPB survey was used to shed light on the participant attitudes, norms, and perceived behavioral control factors on a daily basis. Interestingly, the answers to the postexperiment TPB survey showed that the major control factors (e.g., the ease/difficulty of operating the window-blinds and light switch, also the impact of glare on the use of window-blind) in IVE 
were perceived the same way as in in-situ. This is in line with the authors' previous research [31] indicating that the control beliefs and actual control factors could be perceived as comparably easy/difficult as in the in-situ, if the design of the virtual setting upholds a fair ecological validity.

\section{CONCLUSIONS AND FUTURE RESEARCH}

The authors explored a data collection method applied to IVEs using the STED modelling approach. IVE data from a single occupancy office were collected in a few hours to compare with one-month in-situ data. One hundred twenty-six IVE data that were classified into six event categories were compared with one hundred twenty-eight $i n$-situ data. State transitions as a result of human building interactions were used to test if the proposed STED modeling approach is effective in simulating longitudinal data collection in IVEs. The hypotheses of the study was that the probabilities of the occupancy/lighting state transitions in a given event across the two experimental environments (i.e. IVE vs. in-situ) are not statistically different. Results were promising in producing comparable patterns between the two environments at majority of the events. This suggests that the application of STED can potentially alleviate IVE's weakness for producing predictive models. It should be noted that the goal of this research was not to generalize the results of this case study across other samples such as different people, but it was intended to initially discover the capability of IVEs representing extended observations, using STED.

Even though there were some limitations in the case study (i.e., technology limitation), several important findings could be drawn based on the results of the data analysis. First, regarding the STED modeling approach, the case study shows that the flexibility of the event and spatialtemporal structures allows researchers to organize data based on the need of a study. The results hold good potentials to support not only conventional validation studies, but also collecting longitudinal data for predictive modeling. These potentials, with further proofs, can transform 
IVEs as an experiment platform. However, since the STED modeling approach is intended to cover a long-time study span in IVEs for longitudinal data collection, there often exists a time mismatch between IVE scenarios and experiments. For example, an IVE scenario is about winter conditions and the experiment might be carried out in summer time. Thus, more research is needed to understand the impact of a participant's actual physiological and psychological state on IVE experiments in order to collect data in IVEs within a limited timeframe. Previous researches found evidence that a conventional IVE is capable of eliciting human responses to stimuli such as lighting [30,45], but for an IVE to be able to fully support occupant energy consumption behaviors, more complex IVE systems with additional sensory modalities as well as considering more careful participant inclusion criteria would be necessary. The authors conducted some pilot tests [32,33] to explore the feasibility of IVE's in inducing individuals' naturalistic physiological and psychological responses to temperature as the stimulus. Even though in a sample wise comparison, no statistical difference were found between the studied measures across the IVE and the in-situ, measurements of some participants varied significantly between the two settings. It is still unknown that what variables contribute the most to the mismatch of the in-situ experiences comparing to those in the IVE. Apparently, responses to the visual stimuli (e.g. lighting) can be provoked relatively faster and more naturalistic than some other sensory stimuli (e.g. thermal and air flow). Knowing the fact of how different various sensory systems function, one can accommodate the experimental design accordingly.

Furthermore, the study also shows that the accuracy of IVE cues is very important. It seems that IVEs support salient events more strongly. Constructing IVEs with an intention to elicit a range of responses relies on the effectiveness of the details in the design of the IVEs, especially cues. Since it is not practical to replicate every single in-situ details in IVEs, a careful design of 
cues is required to be able to elicit a variety of event/states even in less distinguishable events. Currently, a systematic study of cues on eliciting occupant behaviors does not exist and thus requires further research.

Finally, this study demonstrated the potential of the STED modeling approach to support IVEs as an experiment apparatus and a predictive model in the future. Studies in the same vein often only focus on validating IVE experiments with in-situ observations, without further explanations of factors that contribute to discrepancies between in-situ and IVEs experiments. As an alternative to predictive modeling using in-situ data, it is important to show the reliability of any predictions using IVE data. Algorithms to calculate such reliability need to be developed.

\section{ACKNOWLEDGEMENT}

This research was supported by the Louisiana Board of Regents Award No. LEQSF (201617)-RD-C-07 and NSF grant CBET-1805914. Any opinions, findings, and conclusions or recommendations expressed in this material are those of the author(s) and do not necessarily reflect the views of the Louisiana Board of Regents. We would also like to show our gratitude to the Laura Arpan, Ph.D., College of Communication \& Information at Florida State University, for assisting the authors in preparing the questionnaires of this study. 


\section{REFERENCES}

[1] T. Hong, H. Lin, Occupant Behavior : Impact on Energy Use of Private Offices, Asia Conf. Int. Build. Perform. Simul. Assoc. (2012).

[2] K.B. Janda, Building communities and social potential: Between and beyond organizations and individuals in commercial properties, Energy Policy. 67 (2014) 48-55. doi:10.1016/j.enpol.2013.08.058.

[3] G.S. Brager, Benefits of Improving Occupant Comfort and Well-being in Buildings, Proc. 4th Int. Holcim Forum Sustain. Constr. Econ. Sustain. Constr. (2013) 181-194.

[4] N.S. Mahbob, S.N. Kamaruzzaman, N. Salleh, R. Sulaiman, Correlation and Regression Studies of Indoor Environmental Quality (IEQ), Human Productivity, Comfort and Stress Level in Office Buildings, Adv. Sci. Lett. 19 (2013) 342-345. doi:https://doi.org/10.1166/asl.2013.4707.

[5] D. Yan, W. O'Brien, T. Hong, X. Feng, H. Burak Gunay, F. Tahmasebi, A. Mahdavi, Occupant behavior modeling for building performance simulation: Current state and future challenges, Energy Build. 107 (2015) 264-278. doi:10.1016/j.enbuild.2015.08.032.

[6] A. Mahdavi, C. Pröglhöf, 169: Observation-based models of user control actions in buildings, Proc. PLEA 2008 - 25th Conf. Passiv. Low Energy Archit. 2008 Conf. (2008).

[7] P. de Wilde, The gap between predicted and measured energy performance of buildings: A framework for investigation, Autom. Constr. $41 \quad$ (2014) 40-49. doi:10.1016/j.autcon.2014.02.009.

[8] S.S. Intille, Designing a home of the future, Inst. Electr. Electron. Eng. Pervasive Comput. 1 (2002) 76-82. doi:10.1109/MPRV.2002.1012340.

[9] V. Fabi, G. Spigliantini, S.P. Corgnati, Insights on Smart Home concept and occupants' 
interaction with building controls, Energy Procedia. 111 (2017) 759-769. doi:doi.org/10.1016/j.egypro.2017.03.238.

[10] J.K. Day, D.E. Gunderson, Understanding high performance buildings: The link between occupant knowledge of passive design systems, corresponding behaviors, occupant comfort and environmental satisfaction, Build. Environ. $84 \quad$ (2015) 114-124. doi:10.1016/j.buildenv.2014.11.003.

[11] X. Chen, H. Yang, L. Lu, A comprehensive review on passive design approaches in green building rating tools, Renew. Sustain. Energy Rev. 50 (2015) 1425-1436. doi:https://doi.org/10.1016/j.rser.2015.06.003.

[12] W.R. Sherman, A.B. Craig, Understanding virtual reality: Interface, application, and design, Elsevier, 2002.

[13] M. Slater, M. Usoh, Representations Systems , Perceptual Position and Presence in Immersive Virtual Environments, Presence Teleoperators Virtual Environ. 2 (1993) 221233. doi:10.1162/pres.1993.2.3.221.

[14] M. Slater, Place illusion and plausibility can lead to realistic behaviour in immersive virtual environments., Philos. Trans. R. Soc. Lond. B. Biol. Sci. 364 (2009) 3549-57. doi:10.1098/rstb.2009.0138.

[15] T.S. Mujber, T. Szecsi, M.S.J. Hashmi, Virtual reality applications in manufacturing process simulation, J. Mater. Process. Technol. 155-156 (2004) 1834-1838. doi:10.1016/j.jmatprotec.2004.04.401.

[16] M. Slater, P. Khanna, J. Mortensen, I. Yu, Visual Realism Enhances Realistic Response in an Immersive Virtual Environment, IEEE Comput. Graph. Appl. (2009) 76-84. doi:10.1109/MCG.2009.55. 
[17] M. V Sanchez-Vives, M. Slater, From presence to consciousness through virtual reality., Nat. Rev. Neurosci. 6 (2005) 332-339. doi:10.1038/nrn1651.

[18] K.L. Marsh, C.T. Wilkie, P.B. Luh, Z. Zhang, T. Gifford, N. Olderman, Crowd Guidance in Building Emergencies: Using Virtual Reality Experiments to Confirm Macroscopic Mathematical Modeling of Psychological Variables, in: Pedestr. Evacuation Dyn. 2012, Springer, 2014: pp. 197-212.

[19] M. Kinateder, E. Ronchi, D. Nilsson, M. Kobes, M. Müller, P. Pauli, A. Mühlberger, Virtual Reality for Fire Evacuation Research, Fed. Conf. Comput. Sci. Inf. Syst. (2014) 319-327. doi:10.15439/2014F94.

[20] M. Kobes, I. Helsloot, B. de Vries, J. Post, Exit choice,(pre-) movement time and (pre-) evacuation behaviour in hotel fire evacuation-Behavioural analysis and validation of the use of serious gaming in experimental research, Procedia Eng. 3 (2010) 37-51.

[21] C. Mackie, J. Cowden, et al., J. Cowden, D. Bowman, W. Thabet, Desktop and immersive tools for residential home design, in: Proc. Conf. Constr. Appl. Virtual Real., 2004: pp. 6370.

[22] J. Reap, F. Roman, S. Duncan, B. Bras, A survey of unresolved problems in life cycle assessment-Part I goals and scope and inventory analysis, Int. J. Life Cycle Assess. 13 (2008) 290-300.

[23] P.S. Dunston, E. Al., L. Ams, J.D. Mcglothlin, G.C. Lasker, A.G. Kushner, An immersive virtual reality mock-up for design review of hospital patient rooms, Collab. Des. Virtual Environ. (2011) 167-176.

[24] D. Tutt, C. Harty, S.D. Smith, D.D. Ahiaga-Dagbui, Journeys through the CAVE: The use of 3D immersive environments for client engagement practices in hospital design, in: Proc. 
29th Annu. ARCOM Conf. Assoc. Res. Constr. Manag. Read., 2013: pp. 2-4.

[25] D.J. Gerber, Immersive Virtual Environments : Experiments on Impacting Design and Human Building Interaction, (2014).

[26] Y. Shen, et al., A spatially augmented reality sketching interface for architectural daylighting design, Inst. Electr. Electron. Eng. Trans. Vis. Comput. Graph. 17 (2011) 3851.

[27] A. Heydarian, J. Carneiro, D. Gerber, B. Bercerik-Gerber, Immersive virtual environments, understanding the impact of design features and occupant choice upon lighting for building performance, Build. Environ. 89 (2015) 217-228.

[28] A. Heydarian, E. Pantazis, D. Gerber, B. Becerik-Gerber, Use of immersive virtual environments to understand human-building interactions and improve building design, in: Commun. Comput. Inf. Sci., 2015: pp. 180-184. doi:10.1007/978-3-319-21380-4_32.

[29] A. Heydarian, E. Pantazis, J.P. Carneiro, D. Gerber, B. Becerik-Gerber, Lights, building, action: Impact of default lighting settings on occupant behaviour, J. Environ. Psychol. 48 (2016) 212-223. doi:10.1016/j.jenvp.2016.11.001.

[30] A. Heydarian, J.P. Carneiro, D. Gerber, B. Becerik-Gerber, T. Hayes, W. Wood, Immersive virtual environments versus physical built environments: A benchmarking study for building design and user-built environment explorations, Autom. Constr. 54 (2015) 116126. doi:10.1016/j.autcon.2015.03.020.

[31] S. Saeidi, L. Arpan, Y. Zhu, T. Rizzuto, N. Johannsen, An Investigation on Occupant Behavior and Building Performance Using Immersive Virtual Environment (IVE), in: 21st Int. Conf. Advacncement Constr. Manag. Real Estate, Hong Kong, 2016.

[32] S. Saeidi, Y. Zhu, J.-H. Choi, C. Zhong, Q. Wang, Immersive Virtual Environment as an 
Apparatus for Occupant Behavior Studies, in: Conf. Constr. Appl. Virtual Real. 2016, Hong Kong, 2016.

[33] S. Saeidi, A. Lowe, N. Johannsen, Y. Zhu, Application of Immersive Virtual Environment (IVE) in Occupant Energy-use Behavior Studies Using Physiological Responses, in: Congr. Comput. Civ. Eng. Proc., ASCE, Seattle, WA, 2017.

[34] M.A. Rosenberg, E.W. Frees, J. Sun, P.H. Johnson Jr, J. Robinson, Predictive modeling with longitudinal data: A case study of Wisconsin nursing homes, North Am. Actuar. J. 11 (2007) 54-69.

[35] D.R.G. Hunt, The use of artificial lighting in relation to daylight levels and occupancy, Build. Environ. 14 (1979) 21-33. doi:10.1016/0360-1323(79)90025-8.

[36] OSHA, Indoor Air Quality Investigationr, United States Occupational Safety and Health Administration (OSHA), (2003) retrieved from: https://www.osha.gov/dts/osta/ot.

[37] M.R. Endsley, Situation awareness global assessment technique (SAGAT), in: Proc. Inst. Electr. Electron. Eng. 1988 Natl. Aerosp. Electron. Conf., 1988: pp. 789-795. doi:10.1109/NAECON.1988.195097.

[38] M.S. Rea, The IESNA lighting handbook: reference \& application, (2000).

[39] C. Reinhart, F, J. Mardaljevic, Z. Rogers, Dynamic Daylight Performance Metrics for Sustainable Building Design, J. Illum. Eng. Soc. North Am. 3 (2006) 7-31. doi:10.1582/LEUKOS.2006.03.01.001.

[40] C. Chokwitthaya, S. Saeidi, Y. Zhu, R. Kooima, The Impact of Lighting Simulation Discrepancies on Human Visual Perception and Energy Behavior Simulations in Immersive Virtual Environment, in: Comput. Civ. Eng. 2017, 2017: pp. 390-398.

[41] I. Ajzen, The theory of planned behavior, Organ. Behav. Hum. Decis. Process. 50 (1991) 
179-211.

[42] J. Lessiter, J. Freeman, E. Keogh, J. Davidoff, A cross-media presence questionnaire: The ITC-Sense of Presence Inventory, Presence. $10 \quad$ (2001) 282-297. doi:https://doi.org/10.1162/105474601300343612.

[43] B.G.S.M.J. Witmer, Measuring Presence in Virtual Environments: A Presence Questionnaire, Presence Teleoperators Virtual Environ. 7 (1998) 225-240. doi:10.1162/105474698565686.

[44] D. Villani, C. Repetto, P. Cipresso, G. Riva, May I experience more presence in doing the same thing in virtual reality than in reality? An answer from a simulated job interview, Interact. Comput. 24 (2012) 265-272. doi:https://doi.org/10.1016/j.intcom.2012.04.008.

[45] S. Saeidi, T. Rizzuto, Y. Zhu, R. Kooima, Measuring the Effectiveness of Immersive Virtual Environment for the Modeling and Prediction of Occupant Behavior, in: 1st Int. Symp. Sustain. Hum. Build. Ecosyst., 2015. 


\section{APENDICES}

1. Theory of Planned Behavior (TPB); pre-experiment survey

\begin{tabular}{lll}
\hline Attitude & A1 & $\begin{array}{l}\text { Opening window-blinds during the day to use natural light instead of turning } \\
\text { on the lights is beneficial. }\end{array}$ \\
\cline { 2 - 3 } & A2 & $\begin{array}{l}\text { Opening window-blinds during the day to use natural light instead of turning } \\
\text { on the lights can help protect the environment. }\end{array}$ \\
\cline { 2 - 3 } Social Norm & SN1 & $\begin{array}{l}\text { I have a natural tendency to open the window-blinds and use the sun light. } \\
\text { Most people like me usually open the window-blinds during the day to use } \\
\text { natural light instead of turning on the lights. }\end{array}$ \\
\cline { 2 - 3 } $\begin{array}{l}\text { SN2 } \\
\text { Norm }\end{array}$ & $\begin{array}{l}\text { Most people I care about expect me to open window-blinds during the day to } \\
\text { use natural light instead of turning on the lights. }\end{array}$ \\
\hline $\begin{array}{lll}\text { Perceived } \\
\text { Control } \\
\text { Belief }\end{array}$ & PCB1 & $\begin{array}{l}\text { I feel guilty when I don't open the window-blinds during the day to use } \\
\text { natural light instead of turning on the lights. }\end{array}$ \\
\cline { 2 - 3 } & PCB2 & $\begin{array}{l}\text { Sometimes I don't open my office window-blinds because it will make me } \\
\text { feel the office gets hot. }\end{array}$ \\
\cline { 2 - 3 } & $\begin{array}{l}\text { The decision to open the window-blinds and use the outdoor light in my } \\
\text { office is entirely up to me. }\end{array}$ \\
\hline PCB3 & $\begin{array}{l}\text { Sometimes I don't open my office window-blinds because it is difficult to } \\
\text { operate it. }\end{array}$ \\
\hline $\begin{array}{l}\text { Actual } \\
\text { Control }\end{array}$ & ACF1 & $\begin{array}{l}\text { Sometimes I don't open my office window-blinds because I feel it is } \\
\text { inappropriate for me to open the window-blinds in the office. }\end{array}$ \\
\cline { 2 - 3 } & $\begin{array}{l}\text { Sometimes privacy concerns keep me from opening my office window- } \\
\text { blinds. }\end{array}$ \\
\hline ACF2 & $\begin{array}{l}\text { Sometimes I don't open my office window-blinds because of glare or too } \\
\text { much light. }\end{array}$ \\
\hline ACF3 & $\begin{array}{l}\text { I would have been more mindful of using my office window-blinds, if I was } \\
\text { going to pay for the electricity. }\end{array}$ \\
\hline
\end{tabular}


2. Theory of Planned Behavior (TPB); post-experiment

\begin{tabular}{|c|c|c|}
\hline \multirow{4}{*}{$\begin{array}{l}\text { Perceived } \\
\text { Control } \\
\text { Belief }\end{array}$} & PCB1 & $\begin{array}{l}\text { The ease/difficulty of operating and accessing the lighting switch or the } \\
\text { window-blind had effect on my lighting choice. }\end{array}$ \\
\hline & PCB2 & $\begin{array}{l}\text { The decision to open the window-blinds and use the outdoor light in my } \\
\text { office was entirely up to me. }\end{array}$ \\
\hline & PCB3 & $\begin{array}{l}\text { It was too difficult to interact with the window-blinds in the room that is } \\
\text { why I preferred to use the ceiling light. }\end{array}$ \\
\hline & PCB4 & $\begin{array}{l}\text { At some points, I only used ceiling light, because I felt it was } \\
\text { inappropriate for me to open the window-blind in my office. }\end{array}$ \\
\hline \multirow[t]{3}{*}{$\begin{array}{l}\text { Actual } \\
\text { Control }\end{array}$} & ACF1 & $\begin{array}{l}\text { Even though I was in a virtual environment, I felt some privacy concerns } \\
\text { could prevent me from opening window-blinds. }\end{array}$ \\
\hline & $\mathrm{ACF} 2$ & $\begin{array}{l}\text { I was not interested in opening the window-blinds because of glare or too } \\
\text { much light. }\end{array}$ \\
\hline & ACF3 & $\begin{array}{l}\text { I would have been more mindful of using a less energy consuming lighting } \\
\text { choice in my virtual office, if I was going to pay for the electricity. }\end{array}$ \\
\hline
\end{tabular}

